\title{
Effect of boric acid on oxidative stress in rats with fetal alcohol syndrome
}

\author{
IBRAHIM SOGUT ${ }^{1}$, AYSEGUL OGLAKCI ${ }^{2}$, KAZIM KARTKAYA $^{2}$, KEVSER KUSAT OL $^{2}$, \\ MELIS SAVASAN SOGUT ${ }^{3}$, GUNGOR KANBAK $^{2}$ and MINE ERDEN INAL ${ }^{2}$
}

\author{
${ }^{1}$ Department of Medical Services and Techniques, Vocational School of Health Services, Istanbul Bilim University, \\ Istanbul 34394; ${ }^{2}$ Department of Biochemistry, Faculty of Medicine, Eskişehir Osmangazi University, Eskişehir 26480; \\ ${ }^{3}$ Department of Genetics and Bioengineering, Yeditepe University, Istanbul 34755, Turkey
}

Received April 17, 2014; Accepted December 4, 2014

DOI: $10.3892 /$ etm.2014.2164

\begin{abstract}
To the best of our knowledge, this is the first study concerning the effect of boric acid (BA) administration on fetal alcohol syndrome (FAS). In this study, the aim was to investigate prenatal alcohol-induced oxidative stress on the cerebral cortex of newborn rat pups and assess the protective and beneficial effects of BA supplementation on rats with FAS. Pregnant rats were divided into three groups, namely the control, alcohol and alcohol + boric acid groups. As markers of alcohol-induced oxidative stress in the cerebral cortex of the newborn pups, malondialdehyde (MDA), superoxide dismutase (SOD), catalase (CAT) and glutathione peroxidase (GPx) levels were measured. Although the MDA levels in the alcohol group were significantly increased compared with those in the control group $(\mathrm{P}<0.05)$, the MDA level in the alcohol + boric acid group was shown to be significantly decreased compared with that in the alcohol group $(\mathrm{P}<0.01)$. The CAT activity of the alcohol + boric acid group was significantly higher than that in the alcohol group $(\mathrm{P}<0.05)$. The GPx activity in the alcohol group was decreased compared with that in the control group $(\mathrm{P}<0.05)$. These results demonstrate that alcohol is capable of triggering damage to membranes of the cerebral cortex of rat pups and BA could be influential in antioxidant mechanisms against oxidative stress resulting from prenatal alcohol exposure.
\end{abstract}

\section{Introduction}

Depending on its acute or chronic use and the dose, alcohol has toxic effects on the mother and fetus when consumed

Correspondence to: Dr Ibrahim Sogut, Department of Medical Services and Techniques, Vocational School of Health Services, Istanbul Bilim University, 17 Yazarlar Sok, Şişli, Istanbul 34394, Turkey

E-mail: ibrahim.sogut@gmail.com

Key words: boric acid, catalase, fetal alcohol syndrome, glutathione peroxidase, malondialdehyde, superoxide dismutase during pregnancy (1). Its toxic effects have been a topic of investigation for approximately five decades $(2,3)$. At present, fetal alcohol spectrum disorders (FASD) have been shown to include alcohol-related birth defects (ARBD), alcohol-related neurological disorders (ARND) and fetal alcohol syndrome (FAS) (3-5). FAS causes mental retardation and growth deficits together with facial anomalies in newborns from chronic alcohol-consuming mothers (3).

Children born with FAS have certain difficulties including learning, memory, attention span, communication, hearing and vision (6,7). Extreme attention, rehabilitation, education, medical support and major economic resources are required to integrate these children into society $(8,9)$. In order to overcome this social problem, new strategies are required to prevent the teratogenic effects of alcohol on the fetus.

Oxidative stress has been shown to be associated with numerous diseases, including cardiovascular disease, cancer and neurological and endocrinological disorders, and also FAS $(10,11)$. Oxidative stress is the imbalance between the production and breakdown of reactive oxygen species (ROS) by endogenous antioxidants (12). Oxidative stress results in increasing lipid peroxidation $(13,14)$ and also ROS production. As a result, membrane and enzyme function may be damaged via overproduction of ROS (11). Antioxidants such as superoxide dismutase (SOD), catalase (CAT) and glutathione peroxidase (GPx) detoxify ROS.

Boric acid (BA) is an essential trace element for plants, humans and animals to support metabolic events. BA is monobasic but is not a proton donor. Instead, it acts as a Lewis acid, accepting a hydroxyl ion from water and releasing a proton. It has high affinity for $S$-adenosyl methionine (SAM) and oxidized nicotinamide adenine dinucleotide $\left(\mathrm{NAD}^{+}\right)$. BA forms complexes with hydroxyl group-containing glycolipids, glycoproteins and phosphoinositides. By this, it affects membrane integrity, calcium chelator function and redox metabolism. When boron is taken orally, it enters the blood stream quickly and thoroughly. Its urinary excretion rate is $\sim 100 \%(15,16)$. Boron can be used for neutron capture therapy in certain types of cancer (17). It decreases the severity and incidence of inflammatory diseases (18). BA affects calcium, magnesium, potassium, vitamin D, aldehyde dehydrogenase, xanthine oxidase, cytochrome $\mathrm{b}$ reductase, insulin, estrogen, 


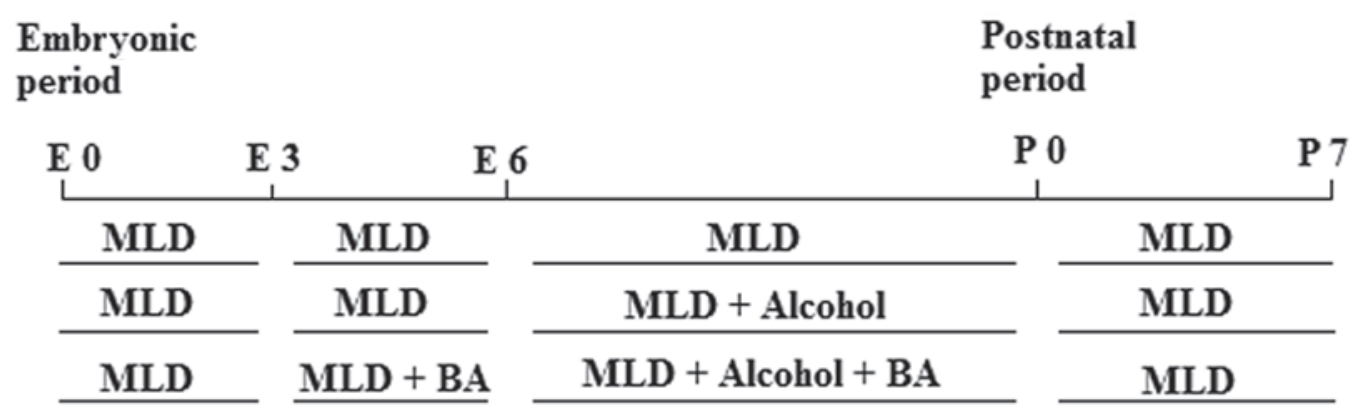

Figure 1. Experimental procedure. E, embryonic day; P, postnatal day; MLD, modified liquid diet; BA, boric acid.

testosterone, T3, T4, triglycerides and glucose metabolism (19). Apart from its diverse functions, previous studies have shown that BA also has antioxidant activity (19-21).

In the current study, the possible protective effect of BA supplementation was evaluated in prenatally alcohol-exposed rats at the cerebral cortex.

\section{Materials and methods}

Experimental procedure. Ten adult male and 30 adult female Sprague-Dawley rats weighing between 200 and $250 \mathrm{~g}$ were created for breeding in the present study. For mating, a male rat was randomly picked up and placed into a female's cage. They were placed in a secluded, temperature- and humidity-controlled room $\left(22 \pm 3^{\circ} \mathrm{C}\right.$ and $60 \pm 5 \%$ respectively) in which a $12: 12 \mathrm{~h}$ light-dark cycle was maintained. The females were checked each morning for the presence of a vaginal plug. The presence of a vaginal plug was considered as evidence of fertilization, and the day the plug was observed was regarded as embryonic day (E) 0 , the first embryonic day. Only in 15 females was a vaginal plug observed, and these were used to set up three experimental groups.

Five pregnant rats were selected for each of the control, alcohol and alcohol + boric acid groups. The animal model of prenatal alcohol consumption was modified from that of Uzbay and Kayaalp (22). The control group was pair-fed with an isocaloric modified liquid diet containing sucrose as a caloric substitute for alcohol (96 g sucrose and $75 \mathrm{ml}$ cows' milk replaced $60.75 \mathrm{~g}$ or $75 \mathrm{ml}$ ethanol). Modified liquid diet (MLD) was given to the alcohol and alcohol + boric acid groups. The MLD comprised $925 \mathrm{ml}$ low fat cows' milk (Sütaş, Istanbul, Turkey), from 25 to $75 \mathrm{ml}$ alcohol $(96.5 \%$ v/v ethanol; Merck Millipore, Darmstadt, Germany) and $17 \mathrm{~g}$ sucrose (Merck Millipore). The calorific content of the diet was $1,000.7 \mathrm{kcal} / \mathrm{l}$. The weight of the rats was recorded every day, and the daily alcohol intake was also measured. The MLD was prepared daily and given to the animals while fresh. Extra chow or water were not available during the experimental period.

At the beginning of the study, the rats were given MLD without alcohol for 6 days (E0-E5). BA was administered prior to alcohol administration (E3-E5) in order to accustom the rats to drinking the supplements. The dosage of BA (Merck Millipore) was $100 \mathrm{mg} / \mathrm{kg}$ (21). Then, a liquid diet with $2.4 \%$ alcohol was administered for 3 days (E6-E8). The alcohol concentration was increased to $4.8 \%$ during the following 3 days (E9-E11) and finally reached $7.2 \%$ over the next 11 days (E11-E22; Fig. 1).

Following delivery, the rats were given MLD without alcohol on postnatal days (P) 0-7. A pool was prepared by selecting two pups from each group of five rats, frozen tissue from this group of pups was used for biochemical analysis. A total of 30 pups $(n=10$ per group) at P7 were used for the study. Pups were sacrificed by decapitation on day P7. The cerebral cortex was surgically removed. Tissues used for biochemical studies were frozen in liquid nitrogen and kept at $-80^{\circ} \mathrm{C}$ until they were tested. All experiments were carried out in accordance with institutional guidelines for animal welfare (Eskişehir Osmangazi University Animal Care and Use Committee, Eskişehir, Turkey) and were approved by the Ethics Committee of the Medical and Surgical Experimental Research Center of Osmangazi University.

Blood alcohol concentration (BAC) measurement. On days E15, E18 and E20, every morning 6 and $22 \mathrm{~h}$ after the administration of fresh diets, a $20-\mu 1$ blood sample was taken from the tails of the rats. Plasma was immediately separated following centrifugation and quantified at $340 \mathrm{~nm}$ to determine the BAC (NAD-ADH Reagent Multiple Test Vial, Sigma-Aldrich, St. Louis, MO, USA) using a Shimadzu UV-1201 spectrophotometer (Shimadzu Corporation, Kyoto, Japan). For each group, on days E15, E18 and E20, a total of six values were obtained as a result of two applications per day (23). The highest of these values was defined as the peak BAC for each group.

Biochemical measurement. Lipid peroxidation was quantified at $532 \mathrm{~nm}$ by the measurement of malondialdehyde (MDA) reacted with thiobarbituric acid (TBA) according to the method of Ohkawa et al (24). The results were expressed in $\mathrm{nmol} / \mathrm{mg}$ protein. SOD activity was determined according to the method of Winterbourn et al (25). One unit of SOD expressed in $\mathrm{U} / \mathrm{mg}$ protein was designated as the amount of enzyme that inhibits the reduction of nitroblue tetrazolium reduction by $50 \%$. CAT activities were calculated using the method of Beutler (26). The reduction in optical density per minute was determined and the enzyme activity was expressed in $\mathrm{U} / \mathrm{mg}$ protein. GPx activity in $\mathrm{U} / \mathrm{g}$ protein was spectrophotometrically determined at $340 \mathrm{~nm}$ using the methods of Paglia and Valentine (27). The protein concentration of homogenates gathered from brain tissues were determined using the Bradford assay (28). 


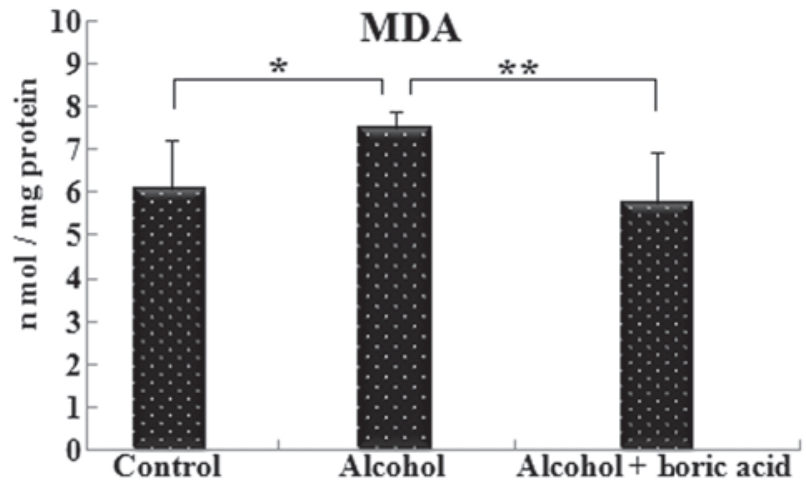

Figure 2. Effect of boric acid on malondialdehyde (MDA) levels in rats exposed to alcohol. ${ }^{*} \mathrm{P}<0.05 ;{ }^{* *} \mathrm{P}<0.01$. Data shown are mean \pm standard deviation.

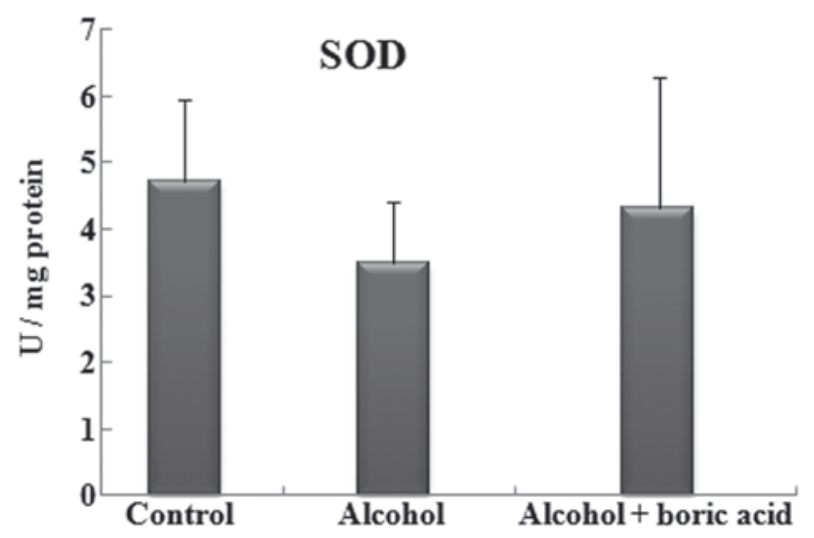

Figure 3. Comparison of superoxide dismutase (SOD) activity among the groups. There were statistically insignificant $(\mathrm{P}>0.05)$ differences among the groups. All data are shown as the mean \pm standard deviation.

Statistical analysis. SPSS software, version 15.0 for Windows (SPSS, Inc., Chicago, IL, USA) was used for the statistical analysis of biochemical data. In order to assess differences between groups, one-way analysis of variance (ANOVA) and Tukey's multiple comparison test were used. Results are presented as mean \pm standard deviation and $\mathrm{P}<0.05$ was considered to indicate a statistically significant result.

\section{Results}

MDAlevels.MDA levels in the alcohol group $(7.53 \pm 1.41 \mathrm{nmol} / \mathrm{mg}$ protein) were significantly increased $(\mathrm{P}<0.05)$ compared with the control level $(6.11 \pm 1.11 \mathrm{nmol} / \mathrm{mg}$ protein). The MDA level in the alcohol + boric acid group (5.74 \pm 1.22$)$ exhibited a significant reduction $(\mathrm{P}<0.01)$ compared with that in the alcohol group (Fig. 2).

Enzyme activities. No statistically significant differences in SOD activities were identified among the groups. The SOD values in the control, alcohol and alcohol + boric acid groups were $4.73 \pm 1.22,3.50 \pm 0.92$ and $4.31 \pm 1.96 \mathrm{U} / \mathrm{mg}$ protein, respectively (Fig. 3). The CAT activity of the alcohol + boric acid group $(15.55 \pm 3.65 \mathrm{U} / \mathrm{mg}$ protein) was found to be higher $(\mathrm{P}<0.05)$ compared with that of the alcohol group $(10.80 \pm 2.79 \mathrm{U} / \mathrm{mg}$ protein). There was no statistically significant difference $(\mathrm{P}>0.05)$ in CAT activity between the

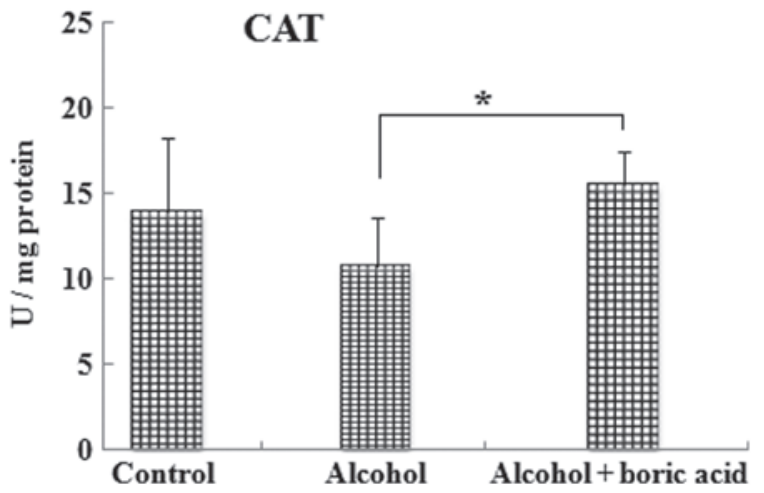

Figure 4. Effect of boric acid on the activity of catalase (CAT) in rats exposed to alcohol. ${ }^{*} \mathrm{P}<0.05$. All data are shown as the mean \pm standard deviation.

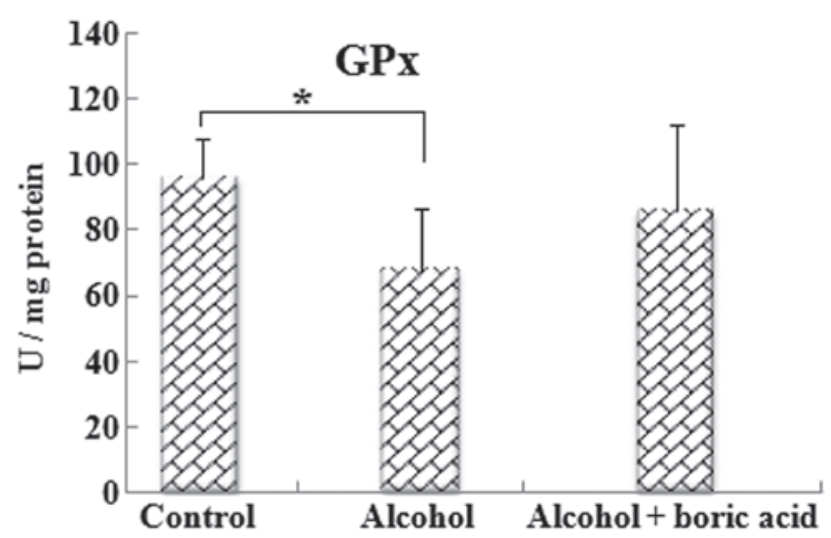

Figure 5. Comparison of glutathione peroxidase (GPx) among the groups. ${ }^{*} \mathrm{P}<0.05$. All data are shown as the mean \pm standard deviation.

control group $(13.90 \pm 4.34 \mathrm{U} / \mathrm{mg}$ protein) and the alcohol group $(10.80 \pm 2.79 \mathrm{U} / \mathrm{mg}$ protein; Fig. 4). GPx activity in the alcohol group $(67.49 \pm 18.88 \mathrm{U} / \mathrm{mg}$ protein) was decreased $(\mathrm{P}<0.05)$ as compared with that in the control group $(95.70 \pm 25.85 \mathrm{U} / \mathrm{mg}$ protein). The GPx activity of the alcohol + boric acid group $(85.67 \pm 29.71 \mathrm{U} / \mathrm{mg}$ protein) was not significantly different $(\mathrm{P}>0.05)$ from that on the other two groups (Fig. 5).

Blood alcohol levels. The highest blood alcohol levels recorded in the two alcohol-administered groups were between 175 and $182 \mathrm{mg} / \mathrm{dl}$.

\section{Discussion}

To the best of our knowledge, this is the first study concerning the effect of BA administration on rats with FAS and the possible antioxidant mechanisms. Alcohol may have direct and indirect effects on the brain. The direct effect of alcohol results in diffusion from the lipid barrier of the cell membrane and increased flowability in the membrane. Oxidative and non-oxidative metabolisms are associated with the indirect effects of alcohol (29). Acetaldehyde is generated, and as a result of forming protein adducts, acetaldehyde disrupts mitochondria and restorative enzymes, leading to the formation of reactive oxygen species. Furthermore, acetaldehyde 
causes a reduction in the number of glutathione groups and hydrophobic regions at the cell membrane and mitochondrial membranes (30). Fatty acid ethyl esters are produced as a result of non-oxidative metabolism, preventing the esterification of cholesterol on neuronal membranes and also disrupting mitochondrial and myelin metabolism (31). It is well-documented that oxidative stress-induced by alcohol-associated mechanisms gives rise to cell damage.

The constitutive formation of oxidants can be balanced by the production of antioxidants at a similar rate. The imbalance between oxidants and antioxidant species causes oxidative stress, resulting from the peroxidation of lipids. MDA is one of the end products in the lipid peroxidation process $(32,33)$. In the present study, prenatal alcohol intake increased the level of lipid peroxidation. These findings are in line with previous fetotoxicity studies $(34,35)$. Enzymatic (SOD, CAT and GPx) and non-enzymatic (thiol and GSH) antioxidants have important roles in preventing the damage resulting from alcohol-induced ROS (11). When female rats were exposed to alcohol during gestation, GPx activity decreased while SOD and CAT activities were not significantly affected (36). In a study concerning free radical formation in rat brains exposed to acute doses of ethanol, it was demonstrated that in the early postnatal period while ROS levels increased, GPx activity decreased (37). Accordingly, chronic alcohol exposure has been shown to decrease cytosolic and mitochondrial GPx activity by 40 and $30 \%$, respectively, in rat liver (38). The steady activity levels of enzymatic antioxidants, namely SOD and CAT, may be due to levels of those enzymes being higher in an adult rat than in a fetus. Furthermore, the activities of these enzymes have been shown to be lower in the brain than other tissues, for example, in the liver and kidney (11).

At present, the complete antioxidant mechanism of BA is not fully understood (39); however, BA is a well-known component of cell membrane functions and enzymatic reactions $(40,41)$. In a previous study, boron supplementation $(100 \mathrm{mg} / \mathrm{kg} /$ day $)$ was shown to decrease lipid peroxidation by enhancing antioxidant activity (21). In another study, a $100-\mathrm{mg} / \mathrm{kg} /$ day dose of BA was also used and shown not to be toxic for rodents when administered for a short period ( $\leq 4$ weeks) (42). According to the proposed hypothesis, a possible mechanism for the decline of alcohol-induced lipid peroxidation might be the increasing levels of SAM with BA administration. Being a Lewis acid, BA may form complexes with many biological compounds through its hydroxyl groups. It has high affinity for SAM, which is known as a methyl donor in biochemical processes, a metabolite in the transsulfuration pathway and a precursor in the synthesis of polyamines (43). In a previous study, chronic alcohol consumption decreased SAM levels while increasing $S$-adenosylhomocysteine (SAH) levels and decreasing the methylation capacity indicator ratio, SAM/SAH (44). In another study on boron deprivation in the liver, the level of SAM was reported to decrease while the homocysteine level increased (41). As Nielsen (40) indicated, boron balances transmembrane signaling and ion movements with its structural and/or functional properties on the cell membrane. According to this information, in the current study, it is hypothesized that a decline in lipid peroxidation was associated with an increase in the SAM/SAH ratio, resulting in balancing of the cell membrane functions.
In the present study, the blood alcohol level reached $175-182 \mathrm{mg} / \mathrm{dl}$ in the alcohol group. This level might lead to impairment in prenatal development since it has been reported that a BAC $>100 \mathrm{mg} / \mathrm{dl}$ in pregnant rats can impair embryo-fetal development (45). The alcohol + boric acid group had no significant change in SOD and GPx activities compared with the alcohol group. SOD and GPx inactivate superoxide and hydrogen peroxide, respectively. In an earlier study of BA supplementation in rats, SOD activity was not affected in erythrocytes or in heart and liver tissues (21). Paralleling the results of the present study, SOD activity was found to be unchanged in another study conducted to assess the effect of $\mathrm{BA}$ on the redox status of the rat liver (46). However, in those studies, BA increased GPx activity. Turkez et al demonstrated that when boron compounds were administered at low doses $(15 \mathrm{mg} / \mathrm{l})$, the CAT activity of erythrocytes increased, whereas high doses $(500 \mathrm{mg} / \mathrm{l})$ of boron led to decreased CAT activities (20). In a study of carbon tetrachloride-induced toxicity in rats, it was shown that BA administration at various doses $(50,100$ and $200 \mathrm{mg} / \mathrm{kg}$ ) increased the CAT enzyme activity in the liver (19). Placental transfer from the mother to fetus and the presence of CAT in the fetus are responsible for the presence of aldehydes in fetal rat brains (47). In the present study, the increasing CAT activity following BA administration may stem from the ability of BA (a Lewis acid) to accept a hydroxyl ion. BA potentially has two crucial functions in this mechanism. Firstly, it detoxifies hydrogen peroxide derived from alcohol by converting it into peroxyboric acid. Secondly, BA converts the CAT enzyme to its native state and maintains the enzyme.

In summary, alcohol-related oxidative stress of cell membranes can be decreased by BA supplementation. According to the results of this study, BA has no impact on blood alcohol levels, but may be a great candidate for use in the protection and regulation of brain membranes. However, future studies are required to evaluate this recovery effect of BA on FAS.

\section{References}

1. Abel EL and Hannigan JH: Maternal risk factors in fetal alcohol syndrome: provocative and permissive influences. Neurotoxicol Teratol 17: 445-462, 1995.

2. Lemoine P, Harousseau H, Borteyru JP and Menuet JC: Children of alcoholic parents - observed anomalies: discussion of 127 cases. Ther Drug Monit 25: 132-136, 2003.

3. Jones KL and Smith DW: Recognition of the fetal alcohol syndrome in early infancy. Lancet 302: 999-1001, 1973.

4. May PA, Gossage JP, Kalberg WO, et al: Prevalence and epidemiologic characteristics of FASD from various research methods with an emphasis on recent in-school studies. Dev Disabil Res Rev 15: 176-192, 2009.

5. Burd L and Martsolf JT: Fetal alcohol syndrome: diagnosis and syndromal variability. Physiol Behav 46: 39-43, 1989.

6. Ahveninen J, Escera C, Polo MD, Grau C and Jääskeläinen IP: Acute and chronic effects of alcohol on preattentive auditory processing as reflected by mismatch negativity. Audiol Neurootol 5: 303-311, 2000.

7. Sampson PD, Streissguth AP, Bookstein FL and Barr HM: On categorizations in analyses of alcohol teratogenesis. Environ Health Perspect 108 (Suppl 3): 421-428, 2000.

8. Abel EL and Sokol RJ: A revised conservative estimate of the incidence of FAS and its economic impact. Alcohol Clin Exp Res 15: 514-524, 1991.

9. Fast DK, Conry J and Loock CA: Identifying fetal alcohol syndrome among youth in the criminal justice system. J Dev Behav Pediatr 20: 370-372, 1999. 
10. Cornelli U: Antioxidant use in nutraceuticals. Clin Dermatol 27 175-194, 2009.

11. Brocardo PS, Gil-Mohapel J and Christie BR: The role of oxidative stress in fetal alcohol spectrum disorders. Brain Res Rev 67: 209-225, 2011.

12. Sies H: Oxidative stress: from basic research to clinical application. Am J Med 91 (Suppl 3): 31S-38S, 1991.

13. Cohen-Kerem R and Koren G: Antioxidants and fetal protection against ethanol teratogenicity. I. Review of the experimental data and implications to humans. Neurotoxicol Teratol 25: 1-9, 2003.

14. Bandyopadhyay U, Das D and Banerjee RK: Reactive oxygen species: Oxidative damage and pathogenesis. Current Sci 77: 658-666, 1999.

15. Nielsen FH: Is boron nutritionally relevant? Nutr Rev 66: 183-191, 2008

16. Hunt CD: Boron. In Encyclopedia of Dietary Supplements 1st edition. Coates PM, Blackman MR, Cragg GM, Levine M, Moss J and White JD (eds). Marcel Dekker, New York, NY, pp55-65, 2005.

17. Altieri S, Bortolussi S, Bruschi P, et al: Neutron autoradiography imaging of selective boron uptake in human metastatic tumours. Appl Radiat Isot 66: 1850-1855, 2008.

18. Hunt CD and Idso JP: Dietary boron as a physiological regulator of the normal inflammatory response: A review and current research progress. J Trace Elem Exp Med 12: 221-233, 1999.

19. Ince S, Keles H, Erdogan M, Hazman O and Kucukkurt I: Protective effect of boric acidagainst carbon tetrachloride-induced hepatotoxicity in mice. Drug Chem Toxicol 35: 285-292, 2012.

20. Turkez H, Geyikoğlu F, Tatar A, Keleş S and Ozkan A: Effects of some boron compounds on peripheral human blood. Z Naturforsch C 62: 889-896, 2007.

21. Ince S, Kucukkurt I, Cigerci IH, Fatih Fidan A and Eryavuz A The effects of dietary boric acid and borax supplementation on lipid peroxidation, antioxidant activity, and DNA damage in rats. J Trace Elem Med Biol 24: 161-164, 2010.

22. Uzbay IT and Kayaalp SO: A modified liquid diet of chronic ethanol administration: validation by ethanol withdrawa syndrome in rats. Pharmacol Res 31: 37-42, 1995.

23. Jiang Q, Hu Y, Wu P, et al: Prenatal alcohol exposure and the neuroapoptosis with long-term effect in visual cortex of mice. Alcohol Alcohol 42: 285-290, 2007.

24. Ohkawa H, Ohishi N and Yagi K: Assay for lipid peroxides in animal tissues by thiobarbituric acid reaction. Anal Biochem 95 351-358, 1979

25. Winterbourn CC, Hawkins RE, Brian M and Carrell RW: The estimation of red cell superoxide dismutase activity. J Lab Clin Med 85: 337-341, 1975.

26. Beutler E (ed): Catalase. In Red Cell Metabolism. A Manual of Biochemical Methods. 3rd edition. Grune and Stratton, New York, NY, pp105-106, 1982.

27. Paglia DE and Valentine WN: Studies on the quantitative and qualitative characterization of erythrocyte glutathione peroxidase. J Lab Clin Med 70: 158-169, 1967.

28. Bradford MM: A rapid and sensitive method for the quantitation of microgram quantities of protein utilizing the principle of protein-dye binding. Anal Biochem 72: 248-254, 1976.

29. Sogut I and Kanbak G: In vitro effects of ethanol with aspirin on rat brain synaptosomes: the potential protective role of betaine. Int J Neurosci 120: 774-783, 2010.
30. Zimatkin SM and Deitrich RA: Ethanol metabolism in the brain Addict Biol 2: 387-400, 1997

31. Bora PS and Lange LG: Molecular mechanism of ethanol metabolism by human brain to fatty acid ethyl esthers. Alcohol Clin Exp Res 17: 28-30, 1993

32. Wu D and Cederbaum AI: Alcohol, oxidative stress, and free radical damage. Alcohol Res Health 27: 277-284, 2003.

33. Hagihara M, Nishigaki I, Maseki M and Yagi K: Age-dependent changes in lipid peroxide levels in the lipoprotein fractions of human serum. J Gerontol 39: 269-272, 1984.

34. Amini SA, Dunstan RH, Dunkley PR and Murdoch RN: Oxidative stress and the fetotoxicity of alcohol consumption during pregnancy. Free Radic Biol Med 21: 357-365, 1996.

35. Smith AM, Zeve DR, Grisel JJ and Chen WJ: Neonatal alcohol exposure increases malondialdehyde (MDA) and glutathione (GSH) levels in the developing cerebellum. Brain Res Dev Brain Res 160: 231-238, 2005.

36. Brocardo PS, Boehme F, Patten A, Cox A, Gil-Mohapel J and Christie BR: Anxiety- and depression-like behaviors are accompanied by an increase in oxidative stress in a rat model of fetal alcohol spectrum disorders: Protective effects of voluntary physical exercise. Neuropharmacology 62: 1607-1618, 2012.

37. Shivakumar BR, Anandatheerthavarada HK and Ravindranath V: Free radical scavenging systems in developing rat brain. Int $\mathrm{J}$ Dev Neurosci 9: 181-185, 1991.

38. Bailey SM, Patel VB, Young TA, Asayama K and Cunningham CC: Chronic ethanol consumption alters the glutathione/glutathione peroxidase-1 system and protein oxidation status in rat liver. Alcohol Clin Exp Res 25: 726-733, 2001.

39. Pawa S and Ali S: Boron ameliorates fulminant hepatic failure by counteracting the changes associated with the oxidative stress. Chem Biol Interact 160: 89-98, 2006.

40. Nielsen FH: Nutritional requirements for boron, silicon, vanadium, nickel, and arsenic: current knowledge and speculation. FASEB J 5: 2661-2667, 1991.

41. Hunt CD: The biochemical effects of physiologic amounts of dietary boron in animal nutrition models. Environ Health Perspect 102 (Suppl 7): 35-43, 1994.

42. Weir RJ Jr and Fisher RS: Toxicologic studies on borax and boric acid. Toxicol Appl Pharmacol 23: 351-364, 1972.

43. Nielsen FH: Boron deprivation decreases liver S-adenosylmethionine and spermidine and increases plasma homocysteine and cysteine in rats. J Trace Elem Med Biol 23: 204-213, 2009

44. Stickel F, Choi SW, Kim YI, et al: Effect of chronic alcohol consumption on total plasma homocysteine level in rats. Alcohol Clin Exp Res 24: 259-264, 2000.

45. Driscoll CD, Streissguth AP and Riley EP: Prenatal alcohol exposure: comparability of effects in humans and animal models. Neurotoxicol Teratol 12: 231-237, 1990.

46. Mohora M BL, Boghianu L, Muscurel C, et al: Effects of boric acid on redox status in the rat liver. Romanian J Biophys 12: 77-82, 2002.

47. Hamby-Mason R, Chen JJ, Schenker S, Perez A and Henderson GI: Catalase mediates acetaldehyde formation from ethanol in fetal and neonatal rat brain. Alcohol Clin Exp Res 21: 1063-1072, 1997 